
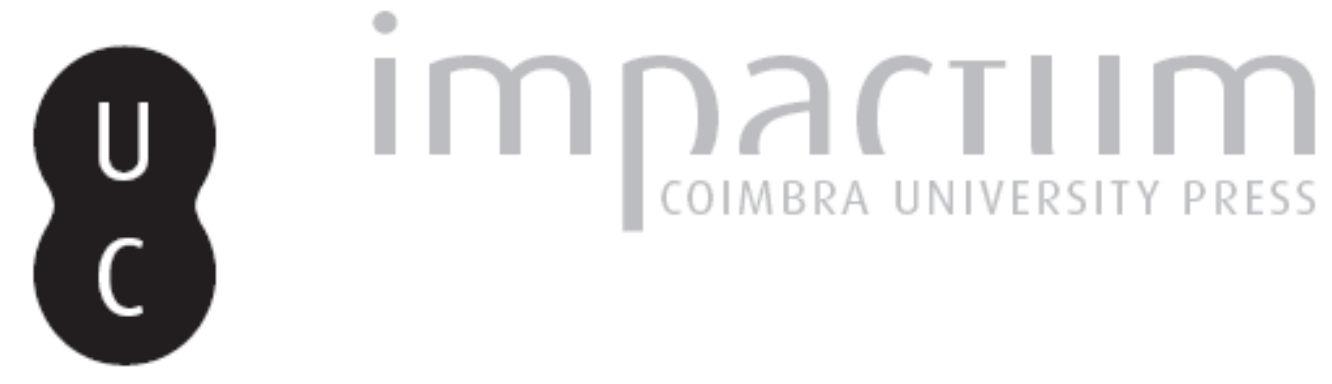

\title{
[Recensão a] Trinidad Nogales Basarrate / María José Pérez del Castillo (Eds.), Ciudades Romanas de Extremadura
}
Autor(es):
Mantas, Vasco Gil

Publicado por: Faculdade de Letras da Universidade de Coimbra

URL

persistente:

URI:http://hdl.handle.net/10316.2/38803

DOI:

DOI:http://dx.doi.org/10.14195/1647-8657_53_9

Accessed : $\quad$ 26-Apr-2023 16:16:36

A navegação consulta e descarregamento dos títulos inseridos nas Bibliotecas Digitais UC Digitalis, UC Pombalina e UC Impactum, pressupõem a aceitação plena e sem reservas dos Termos e Condições de Uso destas Bibliotecas Digitais, disponíveis em https://digitalis.uc.pt/pt-pt/termos.

Conforme exposto nos referidos Termos e Condições de Uso, o descarregamento de títulos de acesso restrito requer uma licença válida de autorização devendo o utilizador aceder ao(s) documento(s) a partir de um endereço de IP da instituição detentora da supramencionada licença.

Ao utilizador é apenas permitido o descarregamento para uso pessoal, pelo que o emprego do(s) título(s) descarregado(s) para outro fim, designadamente comercial, carece de autorização do respetivo autor ou editor da obra.

Na medida em que todas as obras da UC Digitalis se encontram protegidas pelo Código do Direito de Autor e Direitos Conexos e demais legislação aplicável, toda a cópia, parcial ou total, deste documento, nos casos em que é legalmente admitida, deverá conter ou fazer-se acompanhar por este aviso.

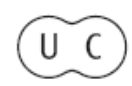


CONIMBRIGA

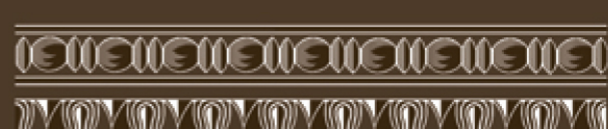

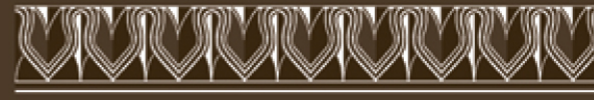

INSTITUTO DE ARQUEOLOGIA

VOLUME LIII • 2014

FACULDADE DE LETRAS 
Trinidad Nogales Basarrate / María José Pérez del Castillo (Eds.), Ciudades Romanas de Extremadura, Studia Lusitana, 8, Mérida, Museo Nacional de Arte Romano, 2014, 260 pp., ilustrado [ISBN: 978-84-617-3695-9].

\section{http://dx.doi.org/10.14195/1647-8657_53_9}

A colecção Studia Lusitana, editada pelo Museo Nacional de Arte Romano de Mérida, foi agora enriquecida com mais um volume de grande interesse, reunindo as conferências apresentadas durante o ciclo subordinado ao tema Ciudades Romanas da Extremadura, realizado no Museu emeritense em 2011. Editado por T. Nogales Basarrate e M. J. Pérez del Castillo, a obra contribui de forma relevante para um ponto da situação do que se conhece sobre as cidades romanas da Estremadura espanhola, cujo território pertence em grande parte à Lusitânia romana. Não deixará de ser interessante comparar o que se publicou em 1990 nas actas da reunião de Talence ${ }^{1}$, início de uma fecunda investigação internacional sobre a Lusitânia, e o que agora se divulga nesta publicação.

Com apresentação das editoras, a obra abre com a sentida evocação, por Paloma Acuña e J. M. Alvárez Martínez, da arqueóloga Manuela Barthélemy. Seguem-se os artigos da responsabilidade de 21 autores, tratando de uma dezena de cidades, maioritariamente lusitanas: Capara, Caurium, Norba Caesarina, Emerita, Ugultunia, Nertobriga, Regina, Metellinum, Augustobriga e Lacimurga. Gostaria de desenvolver uma avaliação dos diversos contributos, que o conjunto da obra merece, mas o espaço disponível não o permite, pelo que me limito a sugerir a sua leitura atenta e a apontar alguns pontos que me parecem mais interessantes.

$\mathrm{O}$ artigo de E. Cerrillo sobre Capara (Ventas de Cáparra) destaca a evolução da cidade e o seu equipamento muito completo para um centro de pequenas dimensões, o que permite distingui-la das civitates sine urbe que pontuam a Beira portuguesa, obrigando a considerar aqui uma realidade diferente. A complicada história arqueológica de Caurium (Cória) é tratada por G. González e J. P. Moreno Carrrasco, que elencam os vestígios de época romana, propondo uma imagem urbana mais realista, sem esquecer a velha discussão sobre a antiguidade da muralha. A referência ao miliário de Augusto

${ }^{1}$ AA.VV, Les villes de Lusitanie Romaine: hiérarchies et territoires, Éditions du Centre National de la Recherche Scientifique, Paris, 1990.

Conimbriga, 53 (2014) 225-233 
achado nos arredores de Cória, pertencente à série de Alfaiates e de Molino del Sobrao, ainda que erradamente datado, considera a necessidade de reinterpretar a rede viária na região².

Seguem-se duas colónias: Norba Caesarina (Cáceres) e Emerita Augus$t a$, cidade que recuperou há pouco anos o estatuto de capitalidade. De Norba ocupam-se E. Cerrillo e T. Nogales, historiando os problemas da arqueologia norbense e centrando a sua intervenção na questão da área monumental da cidade, da localização do forum e do seu programa escultórico e epigráfico, sem esquecer o problema, incómodo, da localização da mansio que servia a cidade. Sobre Emerita no Alto Império escreveram M. Alba, P. Dámaso Sanchéz e G. Sanchéz, defendendo que a cidade foi pensada como um exemplo urbanístico, abrangendo desde o início uma área de 72 hectares. Não creio que assim tenha sucedido, tanto mais que a muralha mostra uma rectificação na zona do anfiteatro, área que estaria antes extra-muros. De qualquer forma, a área atribuída a Emerita ultrapassaria largamente o que se conhece na Lusitânia. Os autores tratam com grande interesse da periferia da colónia, abordagem nem sempre possível e por vezes descurada.

O artigo sobre Ugultunia (Medina de las Torres), da responsabilidade de P. Mateos Cruz, A. Pizzo e V. Mayoral Herrera, reveste-se de grande interesse por confirmar, se tal fosse necessário, o valor da teledetecção e do recurso a métodos geofísicos na arqueologia das cidades antigas como metodologia de prospecção, seguida de validação dos dados através de sondagens, o que permitiu confirmar a existência de um anfiteatro nesta pequena cidade de seis hectares de superfície. A cidade de Nertobriga Concordia Iulia (Fregenal de la Sierra) foi tratada por J. Luís de la Barrera, L. Berrocal-Rangel e R. Caso Amador, que admitem uma municipalização cesariana, tão difícil de provar como noutros sítios peninsulares. O topónimo oficial e a atribuição à tribo Galéria sugerem, creio, alguma reserva. Muito interessante é a presença de dois templos similares e adjacentes, ocupando uma posição dominante no forum, provavelmente consagrados ao culto imperial a crer na epigrafia. Mas o elemento mais invulgar é uma raríssima fossa de fundação escavada junto aos templos e que continha uma relha de arado, datada de finais do século II a.C.

Um pouco mais a sul encontra-se Regina (Casas de Reina), representada por um artigo da autoria de J. M. Alvaréz Martínez, F. G. Rodríguez Martín e T. Nogales. Os autores relacionam o sítio, muito degradado ao longo dos tempos, com a sua localização geográfica e riqueza mineira regional. A referência de Plinio, que a considera um oppidum, e a existência de uma ara consagrada

${ }^{2}$ Todos estes miliários pertencem a uma balizagem efectuada, em 23/22 a.C., imediatamente após a fundação de Mérida. Só através do artigo de Gregório González e Moreno Carrasco conseguimos conhecer a proveniência do miliário depositado no Museo del Cárcel, em Cória, do qual não obtivemos resposta quando o contactámos em 2011.

Conimbriga, 53 (2014) 225-233 
ao Genius Oppidi por um decemvir maximus, sugere, mais uma vez, reflexão sobre o problema dos estatutos urbanos e do significado do título municipal, que aqui remontará aos flávios. Regina parece ter sido uma Dypolis, cujo projecto inicial não se concluiu, talvez por razões económicas. Para além do teatro, felizmente ainda não "requalificado", um dos elementos urbanos mais interessantes é constituído pelos restos muito destruído de três templos edificados contiguamente e que os testemunhos da estatuária sobrevivente não impedem de classificar como um capitólio, onde não faltavam os mármores de Estremoz.

A terceira colónia romana situada na Extremadura é Metellinum (Medellín). O texto respectivo é da autoria de S. Guerra Millán, H. Collado Giraldo, S. Pérez Romero e M. Viola Nevado. O que se verificou neste sítio nos últimos anos transformou por completo a percepção desta cidade, que os arqueólogos referidos aceitam corresponder a Conistorgis, o que me parece por ora, improvado. Apesar de avanços no conhecimento da área urbana, o monumento mais importante continua a ser o teatro, cuja cavea foi parcialmente reconstruída, o que justificou a atribuição do prémio Europa Nostra. Sob a igreja de Santiago identificou-se um templo do período republicano, sugerindo um desenvolvimento inicial a que a fundação de Emerita desferiu um golpe significativo, apesar da atribuição a Metellinum do estatuto colonial por Augusto.

O estudo de Augustobriga (Talavera la Vieja), destruída em 1963 pela barragem de Valdecañas, é da autoria de C. Morán Sanchéz, que desenvolve a história deste sítio arqueológico. Da cidade romana, que terá sido de mediana importância, apenas foram salvos alguns testemunhos, em especial os restos de um dos templos. Mais uma vez deparamos com o impacte da construção de grandes barragens sobre os sítios arqueológicos, quase sempre silenciado. $\mathrm{O}$ autor chama a atenção, todavia, para as oportunidades que os momentos de estiagem proporcionam aos investigadores, pois ficam visíveis vestígios antes desconhecidos, alvo de delapidação imediata. O último estudo, de A. Aguilar Saénz, ocupa-se de Lacimurga (Cierro del Cogolludo), nos limites entre a Lusitânia e a Bética, sublinhando a importância deste sítio no período pré-romano, graças à presença de materiais orientalizantes. Discute também os problemas de identificação e de localização, alargando-se sobre o território e as suas características. Na região achou-se um fragmento de forma cadastral, já publicado por vários investigadores, onde se lê sem dar lugar a dúvidas, o hidrónimo Ana, o verdadeiro nome antigo do Guadiana. O autor sublinha ainda o valor do sítio, deserto e contando com uma importante sucessão de horizontes culturais, como local privilegiado em termos de escavação.

Resta-nos referir a boa qualidade gráfica do volume, como é habitual na colecção Studia Lusitana, convidando os interessados na história e na arqueologia da Lusitânia a apreciarem esta importante publicação, fazendo votos para que o Museo Nacional de Arte Romano prossiga o que já se afirmou como uma relevante iniciativa editorial.

Vasco Gil Mantas

Faculdade de Letras / Universidade de Coimbra

Conimbriga, 53 (2014) 225-233 